\title{
Study on Induced-increasing Traffic during Highway Reconstruction and Extension
}

\author{
Ye Xuanyu ${ }^{1, a}$, Wu Houxuan ${ }^{1, b}$ \\ 1 Jiangxi Ganyue Expressway CO. , LTD , Jiangxi 330025, China \\ a410158466@qq.com \\ b1500844485@qq.com
}

\begin{abstract}
Keywords: Highway reconstruction and extension; Induced-creasing traffic; Induced-creasing traffic time; Induced-creasing traffic strategies

Abstract. The article focuses on the study of induced-creasing traffic during highway reconstruction and extension. The article discusses the principles and characteristics of induced-creasing traffic during highway reconstruction and extension. And then gives the conduction-diffusion model about induced-creasing traffic, and analyzes the efficiency and time of induced-creasing traffic during highway reconstruction and extension. Finally puts forward the strategy of induced-creasing traffic during highway reconstruction and extension.
\end{abstract}

\section{Introduction}

With the increase of traffic volume, some highways have been unable to meet the existing traffic demand.[1] Therefore, a surge of highway reconstruction and extension rises in China. Traffic volume decreases with the reducing of traffic capacity in the process of highway reconstruction and extension.[2] But traffic capacity will be different with the construction of the project. It is necessary to make the traffic volume match to the traffic capacity when it increases, which is the induced-increasing traffic studied in the article.[3,4]

At present, the study of induced-increasing traffic at home and abroad is focused on the period when the highway reconstruction and extension has been completed. While, this article is about the period that the highway reconstruction and extension is underway. The realization of the induced-increasing traffic during highway reconstruction and extension can make full use of the road resources. Scientific and rational measures should be taken step by step for avoiding low traffic efficiency in process of the work for induced-increasing traffic.[5]

\section{The principle and characteristics of induced-creasing traffic}

The generation principle of induced-creasing traffic. From an economics perspective, the root cause of induced-creasing traffic is elastic properties of carriage requirements (elasticity of traffic demand is shown in Figure 1).[6,7] In Figure 1, curve s represents transport supply, curve d is on behalf of transport demand, when the two curves intersect at point $\mathrm{A}$, the balance between supply and demand is achieved. When the traffic is $\mathrm{q}_{0}$, the price of transport is $\mathrm{p}_{0}$. When the highway is in expansion, the relationship between transport supply and demand will change, and transportation supply increases, curve $S$ moves right, changing to $S^{\prime}$. According to the elastic properties of supply and demand, a new equilibrium $\mathrm{B}$ arises, $\mathrm{P}_{1}$ and $\mathrm{q}_{1}$ are correspond price and volume. For the supply curve, traffic congestion level depends on the elasticity of the curve, straight line is an embodiment of perfectly elastic supply, which represents a non-crowded situation; when the highway extension is completed, $S^{\prime}$ is perfectly elastic curve, as shown in figure 1, induced-creasing traffic is maximum at $\mathrm{q}_{1}$ and $\mathrm{q}_{0}$. From above, we can see that the better traffic improvement, the larger the induced-creasing traffic volume will be. 


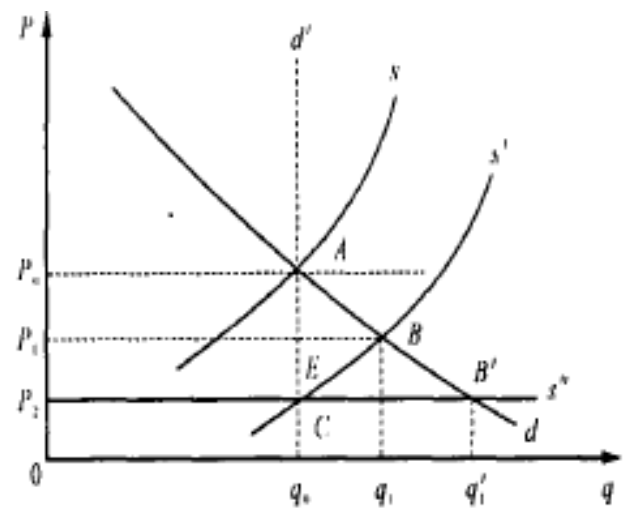

Fig.1 Relationship between transport supply and demand

The Characteristics of Induced-creasing Traffic Volume. In General, the induced-creasing traffic has following features:

(1) Regional. Under the influence of economic factors, the degree of induced-creasing traffic is different due to regional differences.

(2) Lag. Induced-creasing traffic usually appears after a certain time when network changes.

(3) Limited. The growth induced-creasing traffic volume is limited, and when reaching this limit, it will not grow any more.

(4) Difficult to distinguish. It is hard to distinguish induced-creasing traffic volume from the total traffic.

(5) Potential. Affected by the region's economic structure and land layoutetc after the highway is open to traffic, potential traffic volume will arise.

\section{The establishment of conduction-diffusion model about induced-increasing traffic}

According to the characteristics of the induced increasing traffic during highway reconstruction and extension, combining the application of diffusion and conduction equation in physics, we establish one-dimensional conduction diffusion model about induced increasing traffic change:

$$
\left\{\begin{array}{l}
\alpha\left[\frac{\partial \rho}{\partial t}-\frac{\partial}{\partial x}\left(k \frac{\partial \rho}{\partial x}\right)\right]+\beta\left[\frac{\partial \rho}{\partial t}-\frac{\partial}{\partial x}\left(D \frac{\partial \rho}{\partial x}\right)\right]=s(x, t) \\
\square q=\iint s(x, t) d x d t
\end{array}\right.
$$

In the equation , $\alpha, \beta$ represent ratio coefficient of diffusion and conduction about induced increasing traffic respectively, whose values are 0-1, the former is related to road hierarchy,the latter one is related to road network condition surrounding the highway; $k$ represents conductivity factor; $\rho$ represents traffic flow density of the highway; D is diffusion coefficient; $\sqsubset q$ is traffic driving in or out of the project high way.

Next, we simplify the above model.

Assume that traffic flow density $\rho$ is related to location and has nothing to do with time, equation(1) can be simplified as:

$$
(\alpha k+\beta D) \frac{d^{2} \rho}{d x^{2}}=s(x)
$$

We integrate the formula on both sides:

$$
(\alpha k+\beta D) t \frac{d \rho}{d x}+c=\iint s(x) d x d t=\square q
$$

where $c$ is a constant, which can be determined according to actual traffic volume. 
Assume that traffic flow density $\rho$ is related to time and has nothing to do with location, the equation(1) can be simplified as:

$$
(\alpha+\beta) \frac{d \rho}{d t}=s(t)
$$

We integrate the formula on both sides:

$$
(\alpha+\beta) \rho x+d=\iint s(t) d x d t=\square q
$$

where $d$ is a constant.

According to (3) and (5),we can conclude that the traffic driving in or out of the project high way can be expressed as a equation including $\rho$, a positive $\square q$ means traffic driving in, which is traffic that induced increasing.

\section{The analysis of advantages and disadvantages of induced-increasing traffic}

Advantages of induced-increasing traffic. The purpose of induced-increasing traffic is to bring economic and social benefits for road users and operators.

Drivers can obtain the best route through induced by inducing signs and surrounding road network information, reducing the time and fuel cost; at the same time, road operators can increase profit by the way of induced-increasing traffic which can increase traffic of the highway.

The congestion degree mitigation and service levels improving of surrounding road network, the number of parking and emissions reducing are manifestation of Social benefits.

$$
B_{n}=B_{s}+B_{e}-C
$$

Where $B_{n}, B_{s}, B_{e}$ mean net benefit, social benefit and economic benefit brought by the induced-increasing traffic respectively, $C$ means the cost by induced-increasing traffic.

The above equation expresses the net benefit brought by induced-increasing traffic. When the value is positive, it is profitable to take measures to induce traffic. If it is negative, induced-increasing traffic is undesirable. Actual engineering proves that it is profitable to take measures to induce traffic.

Disadvantage analysis of induced-increasing traffic. Although there is benefit of the induced-increasing traffic, the negative impact should not be ignored, which is mainly manifested in traffic congestion risk and traffic safety.

The implementation of induced-increasing traffic measures transfers traffic from surrounding road network to project road, but the project road has not been formally put into operation, so its capacity cannot achieve the ideal value, excessive induced-increasing traffic will bring out traffic congestion on the project road; the increase of traffic density shorten front and back distance between vehicles, bringing hidden danger to the safe operation of vehicle.

\section{Opportunity analysis of induced-increasing traffic in the period of highway reconstruction and extension}

Traffic volume change analysis. According to different periods of highway reconstruction and extension, the expansion project can be divided into three periods, which are the sub-grade widening period, the pavement widening period, the traffic safety facilities and the project ending period. Statuses (taking Chang-zhang expressway as an example) are shown in the following table: 
Table 1. Time division and the traffic diversion situation of highway reconstruction project

\begin{tabular}{|c|c|c|}
\hline $\begin{array}{c}\text { Period } \\
\text { division }\end{array}$ & Road traffic conditions & Traffic diversion condition \\
\hline \multirow{4}{*}{$\begin{array}{c}\text { First } \\
\text { session }\end{array}$} & $\begin{array}{l}\text { Subgrade is widened to the top surface of the } \\
\text { roadbed(Four lanes for normal traffic) }\end{array}$ & Non-shunt \\
\hline & $\begin{array}{l}\text { Upper and lower structure construction of new } \\
\text { bridge(Four lanes for normal traffic) }\end{array}$ & Non-shunt \\
\hline & $\begin{array}{c}\text { New construction and remolding of } \\
\text { overpass(Limited four lane traffic) }\end{array}$ & $\begin{array}{c}\text { Compulsory shunt for Sections } \\
\text { of the road }\end{array}$ \\
\hline & $\begin{array}{l}\text { Expansion of expressway hub interchange } \\
\text { (Limited four lane traffic) }\end{array}$ & Forced Induced diversion mainly \\
\hline \multirow{2}{*}{$\begin{array}{l}\text { Second } \\
\text { session }\end{array}$} & Pavement construction(Limited four lane traffic) & Forced Induced diversion mainly \\
\hline & Bridge deck pavement(Limited four lane traffic) & Forced Induced diversion mainly \\
\hline $\begin{array}{l}\text { Third } \\
\text { session }\end{array}$ & $\begin{array}{l}\text { Traffic safety facilities construction and project } \\
\text { finishing work(Limited eight lane traffic) }\end{array}$ & Induced shunt \\
\hline
\end{tabular}

Analyzing the above table, we obtain that traffic would reduce because of the impact of construction operations which reduce the capacity of the road, and the traffic will maintain at a relatively low level along with the construction of the project until the project road is open to public.

The timing of Induced-increasing traffic analysis. During the highway reconstruction and extension, the traffic diversion ways are different in different periods, as the diversion measures taken, problem of traffic volume does not match the traffic capacity occurs inevitably.[8] Firstly, the traffic demand is greater than road traffic capacity; secondly, traffic demand is less than road traffic capacity. The first case can be eased up by traffic diversion, similarly the second case can be solved by inducing traffic. Analyzing the relationship between traffic supply and demand comprehensively, we conclude that induced-increasing traffic should be performed in the following period:

(1)Time of subgrade settlement

In order to avoid the road uneven settlement, we need to set apart enough time for the settlement after the completion of the roadbed widening construction. At this period of time, construction is suspending, making road traffic capacity increase. But drivers may choose other routes mostly because of the early information publicity, making road resource wasted. So, induced-increasing traffic should be operated.

(2)The end of traffic engineering work

Subgrade and pavement engineering has been finished at this phase. Although the project road has not yet formally put into operation, the traffic capacity is greatly improved, and oversupply is obvious. So timely measures that can increase road traffic should be taken to adapt to the road traffic capacity at this time for the purpose of road resources waste reducing.

\section{Measures of induced-increasing traffic}

According to the market marketing theory, in general, under the premise that products and services meet consumers' demand, consumers regard the net value as the evaluation standard, According to the "customers' net value" concept, when enterprises fight for customer resource with competitors, only by improving the "net value" of their products and the recognition of customers, can they have an advantage in the competition. There are two effective ways for enterprises to improve "customer net value" of their products, which are improving the total products' value that consumers purchase and reducing the total costs.

The path that travelers choose to reach the destination not only needs to meet the basic requirements for safe and economical, but also needs to meet the fast and comfortable conditions in 
the maximum extent. Enterprises should aim at reducing the cost of money, time and energy for travelers as much as possible by improving highway service, so that the "the customer net value "can meet user' requirements. In order to achieve the above standard, the paper gives following specific measures.

(1) Improve the traffic guidance of the convergence section of the highway

The installation of traffic guidance signs is an effective method of induced-increasing traffic during highway reconstruction and extension. Especially, the guidance signs set at convergence which can guide drivers drive into the new highway in order to reach the purpose of traffic inducing. Traffic guidance signs should include instruction signs, guide signs and travel signs, etc. Meanwhile, appropriate number and location should be guaranteed to avoid problems caused by insufficient number and poor recognition.

(2) To strengthen the publicity of road-related information

the premise of induced -increasing traffic is that it can cause interests and bring benefits for the drivers adequately. At the same time, in order to avoid unnecessary loss caused by information lag, information should be propagandized immediately when traffic induction is determined. The main mode includes radio broadcasting, printing brochures, slogans set, variable information display, etc. Promotional information should include:

(1) Available time for driving of the projective road.

We should confirm the traffic induced time according to the projective plan and the progress of project. It should be the beginning of roadbed settlement and ending of traffic engineering period, in order to avoid the hysteresis, the information should be released in advance to facilitate driver selecting route.

(2) Road network condition around the projective road

The induce-increasing traffic come from the surrounding road network, the information of the road network the projective road is helpful for the drivers to drive in the projective road, achieving the purpose of inducing-increasing traffic by attracting traffic from the peripheral road network.

(3) The advantage of the projective road

Through the advantages publicity of project road, it can attract the drivers' attention and induce drivers to choose the project road for their travel route.

(3)Improve the project road service measures

Through taking measures such as traffic signs setting, road information advertising, the traffic volume of project road will increase inevitably. At the moment, we should guarantee the service quality, improving the drivers' satisfaction and retaining existing users on one hand, developing potential users on the other hand. The improvement of the project road service mainly include following aspects: (1) ensure service level of the project road and improve the road service facilities; (2)ensure the service quality of service area, strengthen the service management and public security work, avoid phenomenon of dirty, disorder high fee; (3) strengthen the staff civilization management, put an end to bad service attitude.

(4)Put forward a reasonable speed limit

Traffic environment during construction period is poor, in order to ensure the driving safety, embody the people-oriented concept, a reasonable standard of speed limit must come forward during the period of induced-increasing traffic, and should be strictly carried out. Speed limit standard can be confirmed by speed limit put forward in traffic organization.

\section{Conclusion}

The article analyzes the change of traffic flow during highway reconstruction and extension based on the traffic flow model, and studies the induced-increasing traffic. Different from induced-increasing traffic after the construction, induced-increasing traffic during highway reconstruction and extension need to consider more factors, otherwise it will lead to serious consequences easily. In order to ensure the best "net customer value", and embody the concept of 
"people-oriented", apart from determining the induced time, setting induced facilities and advertising, it also should ensure the limit speed strictly, in order to guarantee the drive safety.

\section{References}

[1] W. Zhou and Y. Wang: Analysis for Induced Traffic Volume on Expressway. Journal of Chang'an University (Natural sciences), 2002, (1): 50-51.

[2] L.H. Yang, X.Q. Zhang and S. An: Study on the Highway Induced Traffic Volume Economic Forecasting. Traffic Engineering Research Center, Harbin University of Technology, Harbin 150090, China.

[3] X.B. Wang: The Traffic Organization Research on Expressway Reconstruction and Extension Engineering. Shanxi Communications Technology. 2010 (01).

[4] M. Cen, H.F. Lin and C. Yang: Highway Induced Traffic Volume Forecast Methods. Shanghai Highway. 2006 (03).

[5] H. Zhang and L. Zhang: Study on Method of Induced Traffic Prediction Based on Gravity Model. Technology of Highway and Transport. 2006(01).

[6] B. Wang, Z.H. Dong and Z.J. Cao: Study on Induced-increasing Traffic Theory. Journal of Hebei University of Technology, 2002. (06).

[7] X.Q. Zhang and S.H. Wang: Study of Highway Traffic Volume Forecasting Based on Economic Growth. Journal of Harbin Institute of Technology. 2007(10).

[8] H. Wang and S.J. Shen: Inducted Traffic and Forecast Model. Journal of Highway and Transportation Research and Development. 2003(03). 